\title{
Investigating stakeholder reactions to a bold salinity policy using
}

\section{a choice experiment}

Jonelle A Cleland, Abbie A Rogers*, Michael P Burton

Centre for Environmental Economics and Policy, M089, School of Agricultural and Resource Economics, The University of Western Australia, 35 Stirling Hwy, CRAWLEY, WA 6009

*Corresponding author contact details: abbie.rogers@uwa.edu.au

CITATION: Cleland, JA, Rogers, AA, Burton, MP 2015, 'Investigating stakeholder reactions to a bold salinity policy using a choice experiment', Land Use Policy, 42: 718-728.

\begin{abstract}
As a statement of policy, the Western Australian Salinity Investment Framework focuses attention on the benefits and costs of outcomes from the abatement of dryland salinity. Policy implementation would result in funds being spent unevenly across the landscape according to the value of assets protected, as well as the costs and effectiveness of treatments. This study used a choice experiment to investigate the reaction of rural stakeholders to the economic principles embodied in the Salinity Investment Framework. The results indicate that what matters is the type of assets protected, the risk of failure and the level of community involvement in the decision-making process; not the distribution of benefits. The results imply that the success of the Salinity Investment Framework, or other prioritised systems of resource management, in terms of community acceptance, does not necessarily rest upon distributional issues, and that other factors play a more crucial role. Policy makers could take this as a signal for the wider acceptance of decision frameworks that promote targeted investment according to public benefit.
\end{abstract}

Key words: choice experiment, dryland salinity, policy, targeted investment, trade-offs. 


\section{Introduction}

Salinity remains a significant problem that severely impacts on agricultural productivity, biodiversity conservation, water supply and infrastructure assets in Western Australia (WA) (National Land and Water Resources Audit 2001, Wallace et al. 2011). The WA Salinity Investment Framework (SIF) was endorsed WA government policy in 2002. It offers a set of principles for prioritising investment decisions that are largely grounded in economic theory (WA State Government 2002a). Foremost, the SIF takes an asset approach, recommending investment in assets that generate the greatest public benefits per dollar of public investment. Thus, the intention of the SIF is to target investment, with limited funds spent unevenly across the agricultural regions of WA.

At the time, endorsing the SIF was a bold move on the part of the State Government with the potential to create tension between the State Government and its major funding partner, the Australian Government. By discouraging uniform patterns of investment in salinity remediation the State Government rejected the underlying logic of national programs (e.g. Landcare, Natural Heritage Trust, National Action Plan for Salinity and Water Quality) which focused on achieving change across the entire landscape by supporting the voluntary actions of landholders and community groups (Curtis \& Lockwood 2000).

The State Government also faced the possibility of political fall-out amongst its rural constituents, with the SIF potentially threatening devolved governance and funding structures put in place from the mid-1990s (Brown 2005). Most notably, regional bodies set their own priorities for investment, with funding tied to requirements set out by the Australian Government. In the environment portfolios, assessments of feasibility and analysis of costs versus benefits were not a precursor to the release of funds. 
In turn, program managers have attempted to preserve the political palatability of large investments in NRM by establishing the perception that funds are distributed equitably (Wallace et al. 2011). As such, key NRM programs have focused, to varying degrees, on (1) building vertical and horizontal partnerships to disburse funds; (2) encouraging broad landholder participation; and (3) building social capacity by including groups marginalised by government decision making in the past, such as women and indigenous peoples.

With the above factors in mind, the implementation of the SIF could be contested by stakeholders on the grounds that it clearly alters the established decision framework for investing in salinity management, with a major issue being that it reduces emphasis on the equitable distribution of funds. Alternatively, the adoption of a decision framework, grounded in economic principles, may appeal to those seeking ways to realise better returns on funds invested and effort expended.

It is likely that the WA State Government anticipated some resistance, or perhaps teething problems with the SIF: they intended the policy to be implemented in stages, with a resourced opportunity to ground-truth the investment framework within the Avon NRM region, prior to it being rolled-out across the remaining WA NRM regions. In a research context, this presented an opportunity to evaluate pre-policy processes, observe policy on the run and test stakeholder reactions to the investment principles embodied in the SIF, as well as their reaction to its implied outcomes (Cleland 2008).

This paper focuses on an investigation, undertaken prior to the SIF implementation, of public reaction to the implied outcomes of alternative policy designs. Using a hypothetical choice experiment administered across the Avon NRM Region in 2003-4 we provide a quantitative assessment of the preferences of stakeholders, and the trade-offs they were willing to make, for 
key elements of the SIF. This will help to identify opportunities and barriers for the wider application of decision frameworks grounded in an 'economic way of thinking'.

\section{Rationale for the choice experiment design}

The SIF is formulated in terms of trade-offs to be made over policy outcomes (e.g. outcomes arising from investment in biodiversity versus rural infrastructure). However, outcomes may be viewed as more, or less, acceptable because of the characteristics of the decision process (e.g. Johnston \& Duke 2007; Rogers 2013). Features of the decision process that can influence the acceptability of the outcome may include the level of trust in decision makers, degree of transparency, provision of effective opportunities for participation and whether there is a mechanism for challenge and dispute resolution (Daniels 2000). The choice experiment methodology provides a mechanism to explore the tradeoffs between elements of a policy design, albeit in a hypothetical context. Understanding the public's reaction to the SIF, in terms of both policy outcomes and the features of the decision process offers greater insights for the real-life application of the policy

Elements relating to both outcome and process can be incorporated into a choice experiment through the careful specification of policy attributes. In light of past decisions and policy positions, we hypothesised that four elements of the SIF would be central when people make judgements about the acceptability of a policy design, and that these elements should underlie the choice experiment design. The four elements were:

1. The type of assets protected (e.g. biodiversity, productive land, public infrastructure);

2. The distribution of benefits;

3. The level of community involvement in the decision process; and

4. The risk of failure. 
The SIF makes it clear that the top priority public investments are those which generate the greatest public benefits per dollar of public investment. Thus, on (1) protection of a particular type of asset will depend on the value of the asset, the cost of preventative treatments and the effectiveness of treatments (WA State Government 2002a). Large areas of farm land will not be a priority for public investment. However, the SIF states that 'where there are extensive private assets at risk, but the public priority is low, public investment should be aimed at industry development' (WA State Government 2002a). Despite the reassurance that landholders wouldn't be left out in the cold, some stakeholders perceived that the SIF was a convenient way for government to withdraw support for landholders who were dealing with salinity (Cleland 2008).

On (2) the SIF is clear on the economic rationale for, and implications of, unequal investment. However, the question of where prioritised salinity investment should end and access to equitable compensation should begin is not outlined. Indeed, some stakeholders were alarmed that the application of the SIF would result in 'winners' and 'losers' and were concerned that their sub-region or locality would completely miss out on funding (Cleland 2008).

On (3) Syme et al. (1999) argue that the provision for community involvement in decision making is a significant determinant of judgements of fairness for the Australian community. Community involvement is implied in the SIF policy statement, with 'communities and government agencies working together in a transparent and participative process' (WA State Government 2002a). However, some stakeholders raised concerns that they were not being adequately engaged and that the SIF was a top-down policy directive (Cleland 2008).

On (4) the SIF places a strong emphasis on investing only where there is a high probability of success (WA State Government 2002a). Here, the reaction of rural stakeholders may be mixed. 
On one hand, it may resonate with those who are disenchanted by the lack of results from past investments (Curtis \& Lefroy 2010). Alternatively, landholders faced with serious salinity problems and limited options may have a sense of urgency to take action and accept associated risks, particularly in terms of providing an opportunity for innovation (Botterill \& Mazur 2004).

The first two elements discussed above are clearly 'outcomes' of the policy, whilst the third element is a policy 'process'. Whether the fourth element, risk of failure, is an outcome or process element depends upon the way it is framed. In terms of outcomes, risk can be simply conceived as the chance that the return on an investment will be different than expected, but is likely to be underpinned by technical factors. In terms of process, risk would capture the pivotal role of socio-political and perceptual factors. The SIF brings the outcome component of risk to the forefront, explicitly noting treatment effectiveness as a criterion for determining the top priority public investments.

The Avon NRM region covers a total area of 117700 square kilometres. Almost $63 \%$ has been released for agriculture and associated land uses; it has a population of over 41000; and more than $6 \%$ is reserved for nature conservation purposes with over 50000 remnants of native vegetation on private land (Australian Government 2011). Over the period 2002 to 2009 the Avon Catchment Council (the body responsible for implementing on-ground actions at that time) received over \$36m in National Action Plan for Salinity and Water Quality and Natural Heritage Trust Program funds (Government of Western Australia, 2010). Given the importance of agriculture, the amount of funding that was being committed to the area and its use as a test bed for the SIF policy, the region provided an ideal location for exploring preferences for agri-environmental policy design. 
The remainder of this paper describes the choice experiment designed to understand the preferences that rural stakeholders hold for the SIF, with the central hypothesis that the type of assets, distribution of benefits, level of community involvement, and risk of failure matter.

\section{Survey design and sampling}

\subsection{Attribute selection}

Attributes were selected to address the four elements expected to explain individuals' preferences for the SIF (see Section 2). It is important to keep in mind that we wanted respondents to evaluate the choice scenarios at a state-wide policy level; that is, with an emphasis on the elements that set the SIF apart from other NRM policies as a decision framework. To satisfy this key requirement, reference to specific geographical areas, assets, or management interventions was entirely avoided. One might expect that respondents would respond differently if the context was a particular project, as opposed to a set of principles on policy that affects all projects, and our objective was to identify values for the broad policy framework.

As such, the asset types are resource categories rather than specific assets, with biodiversity, productive land and public infrastructure selected as independent attributes ${ }^{1}$. It was highlighted in the survey to respondents that biodiversity could occur on both public and private land. They were also briefed that productive land was the area used for the primary purpose of cropping and grazing, and for the survey we would assume that it held negligible biodiversity values ${ }^{2}$.

\footnotetext{
${ }^{1}$ Water was not included as an attribute in the choice experiment due to concerns that it would not be viewed independently from other resource categories (see Blamey et al. 2002). For example, wetlands are often hotspots for biodiversity and the supply of potable water is an important component of public infrastructure.

${ }^{2}$ In this geographical context, this is largely true, although we acknowledge that there is a small body of literature that has identified biodiversity values for lone trees and small patches of trees within productive farmland in Australia (e.g. Fischer et al. 2010, Oliver et al. 2006)
} 
Respondents were also told that whilst both public and private infrastructure can be adversely impacted by salinity, the focus of the SIF was on public infrastructure such as community buildings, streetscapes, major roads, bridge footings, pipes, etc.

The implication of using resource categories is that one cannot easily quantify them in absolute terms (both in terms of initial condition and change in condition) due to either a lack of information, or the possibility that state-wide assessments of condition may jar with a respondent's knowledge or perception of their local area, to the point that they reject the scenarios. As a result, changes in all three resource categories are expressed as a 20 per cent gain, a 20 per cent loss, or no change from the current level. We would argue that the experiment will give accurate estimates of respondents' values for a proportional change in condition, while acknowledging that we cannot identify the current level they believe to exist (but we do explore whether their understanding of the extent of salinity influences the marginal values of changes). Hence, one cannot translate any estimates of the value of protecting assets into absolute values. However, it should be noted that the objective of this paper is to understand trade-offs between policy elements, rather than establish the values of assets.

For consistency and clarity, the remaining attributes were also defined in generic (as opposed to specific) terms (Table 1). The distribution of benefits was put simply as benefits being "equally or unequally distributed across the community". The term "community" was used to emphasise the broader spatial context of NRM policy, and avoid respondents from correlating it to specific personal gains and losses in any of the resource category attributes. The level of community involvement in the decision was framed in familiar terms with 'no consultation' described as government relying on expert opinion alone. A 'consulted' community would have some input into the decision process, whereas an 'empowered' community would have the final say. The risk of failure was framed only in terms of technical uncertainty to emphasise 
the focus of the SIF (see Section 2) and was assigned the categorical levels of low, medium and high.

Conventionally a choice experiment includes a monetary cost, which provides an estimate of the (scaled) marginal utility of income, and hence a basis for calculating monetary partworths. Pilot surveys presented a payment attribute as a tax reallocation needed to finance the policy (Bergstrom et al. 2004; Morrison \& Hatton MacDonald 2011). However, in an analysis of this pilot data, more funds for salinity were preferred irrespective of the other attributes: expenditure on salinity was not seen as a negative in terms of reduced levels of other public good outcomes. This result likely stems from past NRM funding strategies in Australia, in what Watson (2001, p. 26 \& 90) describes as 'chequebook environmentalism' that typifies a 'spend first, think later' approach. Just prior to the field work, taxpayer funded salinity packages were announced by the Australian and Western Australian governments, with regions seeing increased funding levels as a positive outcome for them, irrespective of outcomes (Cleland 2008). Alternatively, it may be that the public struggles with the general concept of scarcity and opportunity costs in relation to government expenditure (King \& Maynard 1999).

Instead of including a monetary cost, respondents were told there was a fixed allocation of funds, which was equivalent for each alternative. This meant that only the marginal rate of substitution (MRS) between attributes could be estimated. Adamowicz (2004) notes that a focus on understanding choice behaviour rather than a focus on value estimates may be a significant advance in valuation applications. In this context, the direction of preferences, in terms of accepting losses and gains, as well as substitution between attributes provides policyrelevant information. 


\subsection{Survey design and implementation}

The survey was designed with input from industry stakeholders, and a series of academic reviews and pilots. An orthogonal, main effects, fractional factorial design ${ }^{3}$ was used for the choice experiment which had nine unlabelled choice sets, each with three alternatives. Relative to an optimal orthogonal design that maximises attribute level differences, our design had a Doptimality measure of 53 per cent (see Street et al. 2005). Each respondent was asked to answer all nine questions within the design.

All three options in the choice scenarios represented a proposed policy change, as a status quo option was not appropriate for this experiment. The focus was on choosing between specific suites of policy attributes that were the product of a given investment decision. There would have been too much conjecture regarding the 'current status' of the policy attributes at the time of the survey. Such judgements would have been value-laden and possibly disenfranchised respondents who did not agree.

Samples were drawn for landholders and townspeople from the three sub-regions of the Avon NRM region (Figure 2). The sample was stratified in this manner because it was hypothesised that the east-west gradient of increasing population density and decreasing farm size could factor in responses. Finer scale maps, supplied by the Water and Rivers Commission were used to reconcile sub-regional boundaries with postal districts (for rural landholders) and town localities (for townspeople). Brylar's Australia on Disc (Dependable Database Data Pty Ltd, November 2002 release) was used as the contact database for rural landholders due to its capacity for spatial manipulation of the dataset and random record tagging. Landholders were recruited by phone. A low refusal rate of one in four was experienced, with the most common

\footnotetext{
${ }^{3}$ The design was generated using the (now-defunct) webdoe online software: see http://archive.today/zADfj)
} 
explanations for not wishing to participate being: too busy, unsure of farming schedule, not very much salt affected land, and ill-health. All landholder surveys were subsequently administered face-to-face on their properties. Townspeople were approached on the street and face-to-face surveys were conducted at this time ${ }^{4}$.

The surveys were conducted from June 2003 to April 2004. The time taken accounts for the large sample size, lengthy interviews, large travel distances between properties and townships, and the seasonality of farming. The landholders sample covered a total of 44 postal districts across the Avon NRM region. In addition, landholders were from properties that varied in distance from the nearest town (i.e. less than 1 kilometre up to 70 kilometres, with a mean distance of 18 kilometres). The townspeople sample covered a total of 23 townships across the NRM region. A total of 126 landholders were interviewed, all of whom provided usable choice data, and 81 townspeople, of whom 79 provided usable choice data. Not all individuals completed all nine choice scenarios in the survey; on average 8.85 and 8.87 were completed by landholders and townspeople, respectively.

The gender ratio for townspeople (57\% male: $43 \%$ female) was similar to that reported for the region as a whole (52:48, derived from Argent 2009). For rural landholders the ratio was skewed towards males (71:29), who are commonly the spokesperson for farming enterprises. Age distributions for both samples aligned relatively well with figures reported by Argent 2009 , apart from an oversampling of those in the $40-50$ age range (39\% and $31 \%$ for farmers and townspeople, compared to $22 \%$ for the Avon Statistical Subdivision).

\footnotetext{
${ }^{4}$ Response rates are not available.
} 


\section{Results}

The results are organised as follows: first, econometric models to estimate the preferences of landholders and townspeople are developed, with consideration of preference heterogeneity between, and within, the two samples; second, the regression output for the landholder and townspeople samples is reported and discussed; and, third, marginal rates of substitution for each of the models are presented. The data were analysed using Stata, version 13 (Statacorp 2009).

\subsection{Model development}

Regression models for landholders and townspeople were generated using a multinomial logit model (McFadden 1974, Train 2009). Each of the biodiversity, land and infrastructure variables were split into two composite dummy variables: one representing the 20 per cent gain level of the attribute (i.e. taking a value of one if present; zero otherwise), the other representing the 20 per cent loss level of the attribute (i.e. taking a value of one if present; zero otherwise), so that differences in preferences for losses versus gains can be considered (Burton et al. 2007; Knetsch 2010).

Because the three alternatives are "unlabelled" one would not expect respondents to show any preference across them, apart from that due to attribute levels (Hoyas, 2010). However, initial analysis indicated that this was not the case, with an apparent preference for the 'central' alternative. Consequently, two alternative specific constants (ASCs) were specified, one for each of the middle and right hand alternatives in the choice scenarios. An ASC measures the utility associated with a particular alternative, separate to the utility for the attribute levels that appear in the alternative. In the unlabelled choice context, the interpretation of these affects must lie with the modes of visual processing (Ossandón, 2014). 
The utility function for individual $n$ (suppressing subscripts for alternatives and repeated choices) is defined as follows for the landholder and townspeople models:

$$
U_{n}=\beta_{a} A S C 2+\beta_{b} A S C 3+\sum_{k=1}^{K}\left(\beta_{k n}+\delta^{\prime} z_{n}\right) x_{k}+\varepsilon_{n}
$$

Where:

$\beta_{a} A S C 2=$ coefficient for the ASC associated with alternative 2

$\beta_{b} A S C 3=$ coefficient for the ASC associated with alternative 3

$k=$ the attributes from the set $K\{1 \ldots 11\}$

$x_{k}=$ vector of policy attributes

$\beta_{k n}=$ vector of marginal utilities of the attributes, $x$

$\delta^{\prime} z_{n}=$ impact $\left(\delta^{\prime}\right)$ of individual characteristic variables $\left(z_{n}\right)$ on the marginal utility of the attributes, $x$

$\varepsilon_{n}=$ unobservable utility

In the multinomial logit model it is assumed that marginal utilities $\left(\beta_{k n}\right)$ are homogeneous across the sample. Individual characteristics $\left(z_{n}\right)$ were relevant in explaining preference heterogeneity with respect to some attributes, and were introduced as interaction terms: time 
spent living in the shire, perceived future threat of salinity, and age of the respondent ${ }^{5}$ (Table 2).

The steps taken to determine the model specifications for landholders and townspeople are summarised below. Likelihood ratio tests ${ }^{6}$ were used within all steps to confirm the appropriate model form (statistical results omitted but available on request).

Step 1 was to test the hypothesis that landholders and townspeople hold homogeneous preferences across the two samples. The samples were pooled, and, controlling for differences in variance using the grid search method (Swait \& Louviere 1993), the equivalence of utility parameters is rejected by a likelihood ratio test. Hence landholder and townspeople samples are treated separately.

Next, we considered the possibility of further heterogeneity existing by allowing for random parameters (see McFadden \& Train 2000, Train 2009). In Equation (1), the attribute marginal utilities, $\beta_{k n}$, can be represented as individual specific draws from a random distribution; that is, there is individual specific heterogeneity in marginal utilities. A mixed multinomial logit (hereafter referred to as a mixed logit) model (Train 2009) was used to estimate the mean and standard deviations of these distributions. Normally distributed random parameters were introduced for the attribute parameters only in each of the models, with individual characteristics shifting the mean of the distribution.

\footnotetext{
${ }^{5}$ The survey collected additional socio-demographic data (including gender, income, education, etc.) however, these variables were not found to be significant in explaning the dependent variables in either of the landholders or townspeople models.

${ }^{6}$ Defined as $2 *($ unrestricted model log likelihood - restricted model log likelihood).
} 
The random parameter specifications were significant in only a limited number of cases. There was no robust representation of landholder preferences that included random parameters, other than on the alternative specific constant for the middle alternative. In the case of townspeople, one attribute parameter, 'Consulted', was consistently found to have a significant standard deviation for the random parameter and was thus included in the model, as well as the alternative specific constant for the middle alternative. The models were estimated using 1000 Halton draws for the random parameter, and panel specification recognising repeated observations. Finally, in cases where the individual characteristic interactions (i.e. using the covariates defined in Table 2) were not significant, they were removed to give the final models (Table 4).

The mixed logit models reported in Table 4 are preferred over the equivalent multinomial logit models, on the basis of likelihood ratio tests. Test statistics of 2.83 and 19.93 for the landholder and rural models, respectively, exceed the critical values of 2.71 and $4.61^{7}$.

Up to this point, we have used dummy variables for the positive and negative changes in the biodiversity, productive land and infrastructure attributes, to allow for the possibility of asymmetry in the values held for equivalent sized gains and losses. One can test for the equivalence of the absolute size of the coefficients associated with gains and losses for each of these attributes using a Wald test. The results (test statistics and $p$ values) are reported in Table 3, and confirm significant differences for all (at the 90 per cent level of confidence or greater), apart from the productive land attribute in the townspeople sample. We therefore redefine the productive land attribute as a continuous cardinal variable $(-20,0,20)$ in the townspeople model.

\footnotetext{
${ }^{7}$ The critical value has to be adjusted to reflect the boundary condition implied by restricting the variance at zero (Gutierrez et al. 2001). An alternative method to test the restriction is using AIC or BIC tests, which leads to the same conclusion.
} 


\subsection{Interpretation of the final models}

The final landholder and townspeople models, with significant interactions, are reported in Table 4. Contrary to our expectations, equity considerations did not play a statistically significant role in the choices of either landholders or townspeople. We return in the conclusions to why this may be the case. Individuals in both samples held positive preferences for reducing the risk of failure from high to medium or low.

In both models, the asset protection attributes for the level of biodiversity and condition of public infrastructure show a clear asymmetry in valuation of gains and losses: respondents are indifferent about positive changes in biodiversity values, relative to no change, while biodiversity loss reduces utility. For landholders, gains in productive land increase utility, while losses reduce utility; however, they react more strongly towards losses in land (Table 3). There is no evidence that townspeople have a similar asymmetry in values for land.

Individual characteristics helped to explain preference heterogeneity for some of the asset protection attributes (Table 4). For both landholders and townspeople, individuals who perceived a higher future predicted extent of salinity showed a stronger aversion to biodiversity losses. Individuals who had spent more time living in the Shire held stronger negative preferences towards biodiversity loss if they were a townsperson, and weaker negative preferences towards biodiversity loss if they were a landholder, ceteris paribus. For townspeople, individuals who had spent more time living in the Shire also held stronger negative preferences towards loss of infrastructure.

Individuals preferred to have some level of community involvement in the decision, rather than none at all (Table 4). Numerically, there was a stronger preference to be consulted rather than empowered, although when evaluated at the mean of age there is no statistical difference between the consulted and empowered marginal utilities (tests of differences yield $p$ values of 
0.25 and 0.55 for landholders and townspeople respectively). However, for townspeople there was a wide distribution of preferences relating to consultation, with some individuals prefering not to be consulted at all. For landholders, the older the individual the stronger their preference to be consulted and empowered; for townspeople, older individuals held weaker preferences for consultation (ceteris paribus).

The ASC estimates indicate a preference for the middle alternative in the choice scenario over and above that which may be ascribed to the levels of the attributes offered in the alternative. This is true for both townspeople and landholder samples, and in both samples the standard error on the random parameter is significant, implying the degree to which the central alternative attracts greater attention varies across the sample. This result cannot be readily explained but perhaps relates to cognitive processing of the choice scenarios (Ossandón et al. 2014).

\subsection{Marginal rates of substitution}

Marginal rates of substitution are estimated as a relative indicator of value, as they control for scale effects and allow us to compare preferences across the landholder and townspeople samples. We have used the area of productive agricultural land as a numeraire, and defined the resulting 'partworths' as the percentage change in productive land that the respondent would be prepared to 'pay' as a trade-off for changes in other attributes. In the case of biodiversity and public infrastructure, this is defined as the amount of land they are willing to lose to avoid a detrimental change (as it is only the changes associated with loss in these variables which are significant), with the change defined as a 20 per cent loss in biodiversity or infrastructure. For community involvement and risk of failure, the partworth is measured as the amount of productive land an individual is willing to lose to gain a beneficial change. 
In the townspeople model, the area of productive land is defined as a cardinal variable, and hence the estimated parameter associated with it can be interpreted in the normal manner: the marginal utility associated with a unit change in agricultural area. In the landholder model, because of the split between gains and losses, the area of productive land is estimated as two dummy variables. Given the difference in the (absolute value of the) estimated values, one potentially has two measures of marginal utility associated with land. We use the value associated with the loss, as we evaluate the partworths as willingness to forgo land to achieve changes in other attributes. We rescale the parameter estimate so that it is the actual percentage of land forgone, rather than the proportion of a 20 per cent loss of land. Unless explicitly stated otherwise, all values are calculated at the sample mean of interaction variables (see Appendix for more detail).

Table 5 shows that landholders and townspeople were willing to give up between 13 and 31 per cent of productive land in exchange for avoiding 20 per cent losses in biodiversity and public infrastructure (statistically significant at the 99 per cent level of confidence). Townspeople were willing to give up roughly twice as much land to avoid these losses, compared to landholders. The level of community involvement in the decision and the risk of failure also had a substantial impact on the amount land that respondents were prepared to give up. An average landholder was willing to give up seven percentage points of productive land to shift from a high risk of failure to a medium risk (statistically significant at the 95 per cent level of confidence), and over 10 percentage points to shift from a high risk to a low risk (statistically significant at the 99 per cent level of confidence). The impact of changing from a high risk of failure to a low risk was greater for an average townsperson (i.e. willing to give up 21 percentage points of land, statistically significant at the 99 per cent level of confidence). This result may be due to townspeople having a greater expectation that public investments in salinity management must yield a public benefit. 
Table 6 shows that the amount of productive land individuals were willing to forgo to achieve an improvement in biodiversity doubled when the perception of future salinity increased from 10 to 75 per cent. Table 6 indicates that increasing the time spent in the Shire by 40 years doubles the amount of land one is prepared to give up for townspeople, while it almost halves the amount for landholders. There is a similar effect for townspeople in relation to avoiding loss of public infrastructure, with the amount of land an individual is prepared to lose increasing with time spent in the shire (Table 8).

The age of the respondent has significant, but opposite, impacts on the value placed on community involvement for the landholder and townspeople samples. For landholders, the older a respondent is the more productive land they are prepared to give up to achieve an increase in level of involvement from no consultation to consultation or empowerment (Table 9). However, the reverse is true for townspeople.

\section{Conclusion}

The findings of this research have both academic and policy application. The study has demonstrated that a choice experiment is an effective way to unbundle a policy and test people's reactions to its various elements. It has provided a powerful analytical framework to gauge the public's response to a policy prior to it being widely implemented. This is a critical point given that policy making occurs in a complex and conflicted arena that is often hindered by lack of evidence (Productivity Commission 2011).

Importantly, the targeted funding aspect of the SIF, which was perceived as a potential barrier prior to the choice experiment, was not as critical as other factors, given the lack of concern respondents placed on the equal or unequal distribution of benefits. 
There are a number of possible explanations for this result. First, cynicism and frustration with past, more egalitarian, policies and programs may help to soften the public's reaction to policies that do not endorse an even spread of funds between regions, catchments, organisations, etc. In the survey, respondents were asked to rate the effectiveness of past programs and over 50 per cent disagreed or strongly disagreed that funds had been used effectively. Further, respondents reported that the top three factors influencing the allocation of funds to salinity were stronger political lobbying, more effective leadership and better communication of the issues. These factors came ahead of better outcomes for the environment, the likely success of the project and larger economic and social consequences (Cleland 2008). Indeed, Pannell et al. (2007) asserts that engaging landholders in works that are unlikely to achieve worthwhile NRM outcomes uses up their valuable time and resources, and in doing so, runs the risk of exhausting the stock of goodwill that landholders have historically bought to their environmental works.

Second, by virtue of design, the choice experiment forced the respondent to evaluate the tradeoffs inherent in the SIF at a very broad level. If the choice experiment was recast to reflect trade-offs at a more local scale, with attributes given a more focused spatial definition, respondents could potentially identify whether they are a 'winner' or 'loser' in the allocation of funds. In turn, more significance may then be placed on the equal or unequal distribution of benefits from investment. Here, we might expect the losers to respond positively to equitable outcomes. However, research by Marshall (2004) found that farmer's preparedness to cooperate in implementing plans was more sensitive to perceptions of community benefits than private materialistic considerations like distributive fairness.

Rural stakeholders had strong positive preferences for alternatives that reduced the risk of failure. This aligns well with the SIF, in terms of supporting investments with a high probability of success. Indeed, comments made by a number of respondents indicated that they were conceptualising public risk rather than private risk in the choice experiment: they noted that a 
lower of level of risk must be taken when using public funds as compared to decisions involving private funds (Cleland 2008).

Whilst rural stakeholders had positive preferences toward community involvement in the investment decision, there is no strong preference for being empowered over being consulted. This may suggest that rural stakeholders are reluctant to take sole responsibility for investment decisions regarding salinity, but still want to be meaningfully consulted. Reasons for not wanting sole responsibility may be based on the perception that they do not have the capacity, in terms of resources, time or skills, to implement the SIF. Alternative explanations can be found in the health literature. Coast (2000) demonstrated that the responsibility of priority setting can weigh heavily on individuals, leading to a type of decision-making disutility. Dolan et al. (1999) also found that given the opportunity for reflection, the public can become more reticent about the importance of their role in determining priorities and more sympathetic to the role of managers.

It should be noted that the study was conducted within a specific temporal and geographical context. There had been substantial funding made available to the region, although not sufficient to resolve the salinity problem. Salinity had a very high profile as a threatening process. It's possible that if a similar study were to be conducted under alternative circumstances that the relative weights placed on elements of the policy would change. It would also be of value to have some international comparisons. Roy et al. (2011) note that targeting investments that deliver environmental goods and services is "an important practice for public accountability purposes and is a prominent feature of EGS programs reviewed in Australia, France, Switzerland, the United States and the United Kingdom”. Moreover, the European Court of Auditors has suggested the need for improved targeting of funding in agrienvironmental schemes within the European context (ECA, 2011). It would be valuable to ascertain the extent to which landholders and the public support such moves. Further 
understanding of the importance of distributional impacts in other jurisdictions would be of value. $^{8}$

It is important to acknowledge that whilst the principles of the SIF remain unaltered, the application of the SIF at a State NRM agency level has seen it evolve across a number of phases (Cleland 2008). The SIF Phase 1 worked through some of the practical issues of prioritising vast lists of assets in various resource categories and established that State Government investment is only likely where assets are of high value and under high threat (i.e. Tier 1 assets, Department of Environment 2003). The SIF Phase 2 worked through considerations of feasibility for the Tier 1 assets. It also established that direct financial assistance to landholders should only occur where it contributes to protecting Tier 1 assets. Support for managing salinity on agricultural land not associated with the top priority assets would come through industry development to provide profitable new options (Sparks et al. 2006).

The next phase of the SIF was meant to see Regional NRM Groups and other key stakeholders consulted to assess what form of 'kit' or information package would enable them to use the data and analyses for their own prioritisation purposes. However, following various criticisms of the national salinity program (e.g. Auditor General 2008) and a change of government at the national level in 2007, funding priorities of the Australian Government were diverted away from salinity to other NRM issues. Consequently, the developers of SIF3 evolved it into the Investment Framework for Environmental Resources (INFFER), a more general environmental investment framework (Pannell et al. 2012). INFFER has been widely used as a means to guide investment is Australia, and its use internationally is growing (see www.inffer.com.au for

\footnotetext{
8 Particularly given Roy et al. (2011) note that "Canadian pilot initiatives are taking into account other socioeconomic criteria such as equity" (p.57).
} 
examples). Acceptance of the principles underpinning the initial bold salinity policy would appear to be growing.

\section{Acknowledgements}

The PhD from which this research is drawn was funded through an Australian Research Council Strategic Partnerships with Industry Research and Training grant, with operational support provided by the WA State Government's Department of Water and the Department of Agriculture and Food. Additional support has been provided via the Australian Government's National Environmental Research Program and the Australian Research Council Centre of Excellence for Environmental Decisions. The useful comments of a number of anonymous reviewers and Professor David Pannell are gratefully acknowledged.

\section{References}

Adamowicz WL (2004) What's It Worth? An Examination of Historical Trends and Future Directions in

Environmental Valuation. Australian Journal of Agricultural and Resource Economics 48, 419-443.

Argent, N (2009) Shifting Demographic Structures of Australian Agricultural Regions. Presentation given at the Healthy Farming - Stronger Communities Workshop, Institute of Agriculture, University of Western

$\begin{array}{lllll}\text { Australia, } & 31 & \text { July } & 2009 & \text { Available }\end{array}$

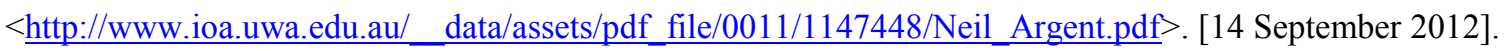

Auditor General, 2008. Regional Delivery Model for the Natural Heritage Trust and the National Action Plan for Salinity and Water Quality, Report No. 21 2007-08, Performance Audit. Australian National Audit Office, Canberra.

Australian Government (2011) Avon NRM Region. Available from: $<$ http://www.nrm.gov.au/about/nrm/regions/wa-avon.html >. [30 March 2012].

Bergstrom JC, Boyle KJ, Yabe M (2004) Trading Taxes vs. Paying Taxes to Value and Finance Public Environmental Goods. Environmental and Resource Economics 28, 533-549. 
Blamey RK, Bennett JW, Louviere JJ, Morrison MD (2002) Attribute Causality in Environmental Choice Modelling. Environmental and Resource Economics 23, 167-186.

Botterill L, Mazur N (2004) Risk and Risk Perceptions: A Literature Review. Rural Industries Research and Development Corporation, Report No. 04/043, Kingston.

Brown AJ (2005) Regional Governance and Regionalism in Australia. In: Eversole R, Martin J (eds) Participation and Governance in Regional Development: Global Trends in a Australian Context, pp. 17-42. Ashgate Publishing Company, Hampshire.

Burton M, Marsh SP, Patterson J (2007) Community Attitudes Towards Water Management in the Moore Catchment, Western Australia. Agricultural Systems 92, 157-178.

Cleland, JA (2008) Western Australia's Salinity Investment Framework: A study of priority setting in policy and practice. PhD thesis, The University of Western Australia, Crawley.

Coast J (2000), Explicit rationing, deprivation disutility and denial disutility: evidence from a qualitative study, in The Global Challenge of Health Care Rationing (eds) A Coulter and C Ham, Open University Press, Buckingham, pp 192-200.

Curtis AL, Lefroy EC (2010) Beyond Threat- and Asset-based approaches to NRM in Australia. Australian Journal of Environmental Management 17, 6-13.

Curtis A, Lockwood M (2000) Landcare and Catchment Management in Australia: Lessons for State-Sponsored Community Participation. Society and Natural Resources 13, 61-73.

Daniels N (2000) Accountability for Reasonableness: Establishing a Fair Process is Easier than Agreeing on Principles. British Medical Journal 321, 1300-1301.

Department of Environment (2003) Salinity Investment Framework Interim Report - Phase 1, Salinity and Land Use Impacts Series, Report No, 32, Perth.

Dolan P, Cookson R, Ferguson B (1999) Effect of Discussion and Deliberation on the Public's Views of Priority Setting in Health Care: Focus Group Study, British Medical Journal 318:916-9 
ECA (2011) Is agri-environnment support well designed and managed? Luxembourg, Court of Auditors Special Report No.7.

Fischer J, Zerger A, Gibbons P, Stott J, Law BS (2010) Tree Decline and the Future of Australian Farmland Biodiversity, Proceedings of the National Academy of Sciences of the United States of America, 107:1959719602

Government of Western Australia (2010) National Action Plan for Salinity and Water Quality and Natural Heritage Trust program 2003-2009 Final Report . Perth, Australia

Gutierrez R, Carter S, Drukker D (2001) On boundary-value likelihood-ratio tests. Stata Technical Bulletin 10, 15.

Hoyos D. (2010) The state of the art of environmental valuation with discrete choice experiments. Ecological Economics 69(8):1595-603.

Johnston RJ, Duke JM (2007) Willingness to Pay for Agricultural Land Preservation and Policy Process Attributes: Does the Method Matter? American Journal of Agricultural Economics 84, 1098-1115.

King D, Maynard A (1999) Public Opinion and Rationing in the United Kingdom. Health Policy 50, 39-53.

Knetsch J (2010). Values of Gains and Losses: Reference States and Choice of Measure. Environmental and Resource Economics 46, 179-188.

McFadden D (1974) Conditional Logit Analysis of Qualitative Choice Behaviour. In: Zarembka P (ed.) Frontiers in Econometrics, pp 105-142. Academic Press, New York.

McFadden D, Train K (2000) Mixed MNL Models for Discrete Response. Journal of Applied Econometrics 15, 447-470.

Martin D, Singer P (2003) A Strategy to Improve Priority Setting in Health Care Institutions. Health Care Analysis $11,59-68$

Mitton C, Prout S (2004) Setting Priorities in the South West of Western Australia: where are we now? Australian Health Review 28, 301-310. 
Morrison M, Hatton MacDonald D (2011) A Comparison of Compensating Surplus and Budget Reallocation with Opportunity Costs Specified. Applied Economics 43, 4677-4688.

National Land and Water Resources Audit 2001 Australia Dryland Salinity Assessment 2000: Extent, Impacts, Processes, Monitoring and Management Options. Land and Water Australia, Braddon.

Oliver I, Pearce S, Greenslade PJM, Britton DR (2006) Contribution of Paddock Trees to the Conservation of Terrestrial Invertebrate Biodiversity Within Grazed Native Pastures, Austral Ecology, 31, 1-12.

Ossandón, J.P., Onat,S., König,P. (2014) Spatial biases in viewing behavior Journal of Vision 14(2): 20

Pannell DJ, Ridley AM, Seymour E, Marsh S, Wilkinson R (2007) Lessons and Implications from the SIF3 Project, SIF3 Working Paper 0708, Future Farm Industries Cooperative Research Centre, Crawley.

Pannell, D.J., Roberts, A.M., Park, G., Alexander, J., Curatolo, A. and Marsh, S. (2012). Integrated assessment of public investment in land-use change to protect environmental assets in Australia, Land Use Policy 29(2): 377387.

Productivity Commission (2011) Independent Policy Advice. PC Update 50, 13-14.

Rogers, AA (2013) Social Welfare and Marine Reserves: Is Willingness to Pay for Conservation Dependent on Management Process? A Discrete Choice Experiment of the Ningaloo Marine Park in Australia. Canadian Journal of Agricultural Economics 61(2): 217-238

Roy,D., Venema,H.,McCandless,M. (2011) Ecological Goods and Services: A review of best practice in policy and programming. International Institute for Sustainable Development Manitoba, Canada.

Sparks T, George R, Wallace K, Pannell D, Burnside D, Stelfox L (2006) Salinity Investment Framework Phase 2, Salinity and Land Use Impact Series, Report No. 34, Perth.

StataCorp (2013) Stata. Release 13, Statistical Software.

Street DJ, Burgess L, Louviere JJ (2005) Quick and Easy Choice Sets: Constructing Optimal and Nearly Optimal Stated Choice Experiments, International Journal of Research in Marketing 22, 459-470.

Swait J, Louviere J (1993) The Role of the Scale Parameter in the Estimation and Comparison of Multinomial Logit Models. Journal of Marketing Research 30, 305-314. 
Syme GJ, Nancarrow BE, McCreddin JA (1999) Defining the Components of Fairness in the Allocation of Water to Environmental and Human Uses. Journal of Environmental Management 57, 51-70.

Train KE (2009) Discrete Choice Methods with Simulation. Cambridge University Press, New York.

Wallace K, Connell K, Vogwill R, Edgely M, Hearn R, Huston R, Lacey P, Massenbauer T, Mullan G, Nicholson N (2011). Natural Diversity Recovery Catchment Program: 2010 Review. Department of Environment and Conservation, Perth, Western Australia.

WA State Government (2002a) A Framework to Guide Investment Decisions in Salinity Management in WA. Reproduced in: Cleland, JA (2008)Western Australia's Salinity Investment Framework: A Study of Priority Setting in Policy and Practice, pp. 430-433. PhD thesis, The University of Western Australia, Crawley.

WA State Government (2002b) Notice of Intent Salinity Investment Framework. Reproduced in: Cleland, JA (2008) Western Australia's Salinity Investment Framework: A Study of Priority Setting in Policy and Practice, pp. 436-437. PhD thesis, The University of Western Australia, Crawley.

Watson A (2001) Money and the Environment. Agenda 8, 89-96. 
Table 1: Description of the attributes used in the choice experiment.

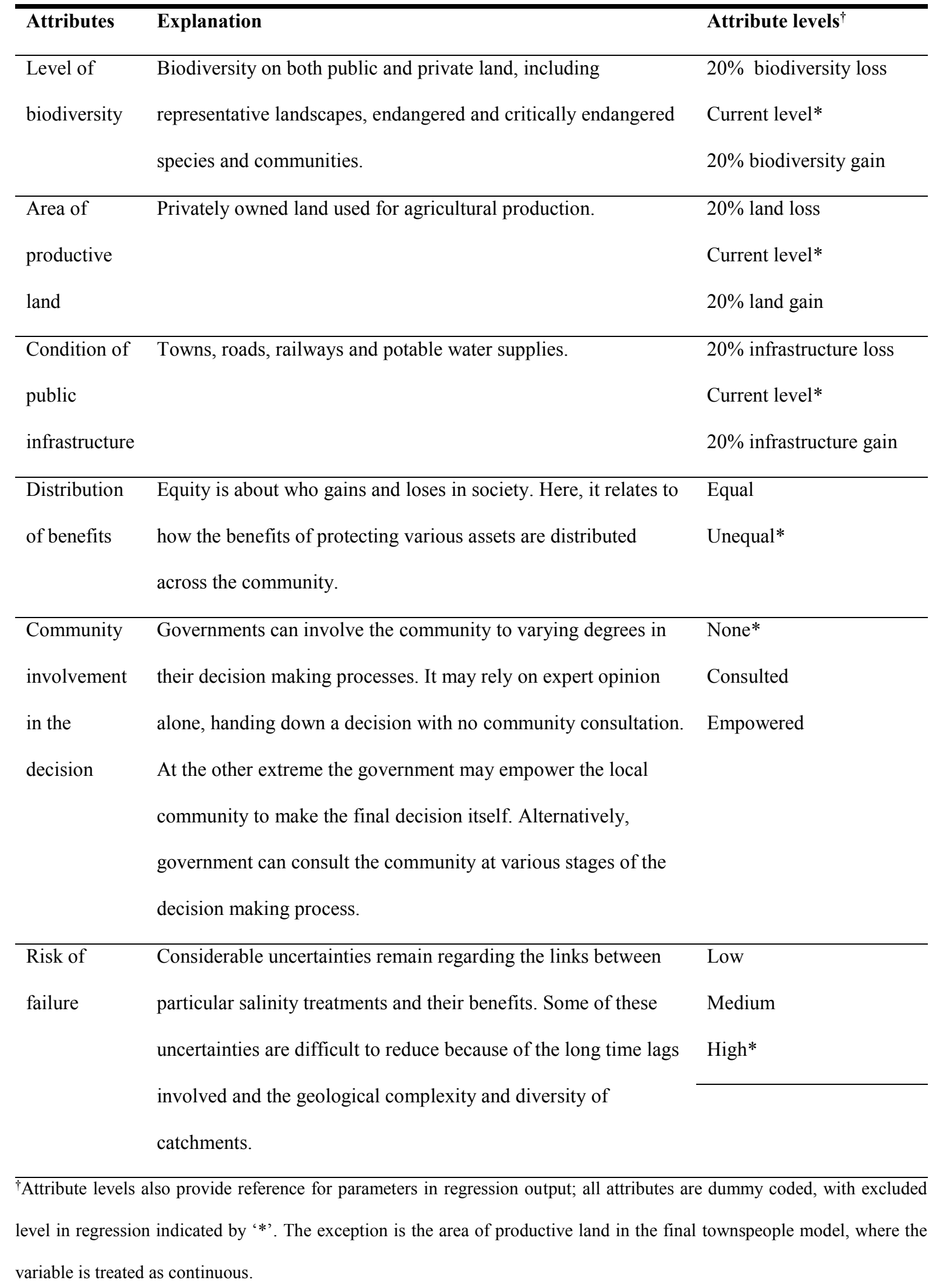


Table 2: Description of individual characteristics specified as covariates in the choice models, with mean sample values noted.

\begin{tabular}{|c|c|c|c|c|c|}
\hline \multirow{2}{*}{$\begin{array}{l}\text { Individual } \\
\text { characteris }\end{array}$} & \multirow{2}{*}{\multicolumn{3}{|c|}{ Description }} & \multicolumn{2}{|c|}{ Mean $^{\#}$} \\
\hline & & & & \multirow{2}{*}{$\begin{array}{l}\text { Landholders } \\
35.1 \text { years }\end{array}$} & \multirow{2}{*}{$\begin{array}{l}\text { Townspeople } \\
22.2 \text { years }\end{array}$} \\
\hline Time & \multicolumn{3}{|c|}{ Time spent living in the shire - years } & & \\
\hline $\begin{array}{l}\text { Perceived } \\
\text { threat }\end{array}$ & \multicolumn{3}{|c|}{ Perceived future threat of salinity - percentage area ${ }^{\dagger}$} & $30.6 \%$ & $37.5 \%$ \\
\hline Age & \multicolumn{3}{|c|}{ Age of respondent - years } & 50.8 years & 47.8 years \\
\hline \multicolumn{6}{|c|}{$\begin{array}{l}{ }^{\dagger} \text { In the survey respondents were presented with a } 0-100 \% \text { scale (in } 5 \% \text { increments) } \\
\text { select either one value on the scale, or a range. We then averaged the value that an ir } \\
\text { they recorded if they selected only one, or the average of any range they selected). }\end{array}$} \\
\hline \multicolumn{6}{|c|}{ \#At estimation, all individual characteristics are defined as sample mean deviations. } \\
\hline \multirow{2}{*}{\multicolumn{6}{|c|}{$\begin{array}{l}\text { Table 3: Wald test statistics, testing (absolute) equivalence of marginal utility for gains anc } \\
\text { losses in the biodiversity, productive land and public infrastructure attributes for the landholder }\end{array}$}} \\
\hline & & & & & \\
\hline \multicolumn{6}{|c|}{ and townspeople models. Evaluated at means of individual specific attributes. } \\
\hline & & \multicolumn{2}{|c|}{ Landholders } & \multicolumn{2}{|c|}{ Townspeople } \\
\hline & & Chi(1) & Prob $>$ Chi2 & Chi(1) & Prob $>$ Chi2 \\
\hline Level of bio & ersity & 13.21 & 0.0003 & 10.86 & 0.0010 \\
\hline Area of proc & tive land & 5.15 & 0.0232 & 1.06 & 0.3037 \\
\hline Condition o & blic infrastructure & 3.50 & 0.0614 & 6.42 & 0.0113 \\
\hline
\end{tabular}


Table 4: Final choice models for landholders and townspeople.

\begin{tabular}{|c|c|c|c|c|}
\hline \multirow[t]{3}{*}{ Variables } & \multirow{2}{*}{\multicolumn{2}{|c|}{$\begin{array}{l}\text { Landholders } \\
\text { Final model }\end{array}$}} & \multirow{2}{*}{\multicolumn{2}{|c|}{$\begin{array}{l}\text { Townspeople } \\
\text { Final model }\end{array}$}} \\
\hline & & & & \\
\hline & \multicolumn{2}{|c|}{ Coefficient (standard error) } & \multicolumn{2}{|c|}{ Coefficient (standard error) } \\
\hline \multicolumn{5}{|l|}{ Level of biodiversity } \\
\hline $20 \%$ biodiversity gain & 0.201 & $(0.160)$ & 0.002 & $(0.176)$ \\
\hline $20 \%$ biodiversity loss & $-1.130 * * *$ & $(0.190)$ & $-0.950 * * *$ & $(0.194)$ \\
\hline $20 \%$ biodiversity loss $*$ time & $0.017 * * *$ & $(0.006)$ & $-0.020 * * *$ & $(0.007)$ \\
\hline $20 \%$ biodiversity loss $*$ perceived threat & $-0.014 * *$ & $(0.006)$ & $-0.0107 * *$ & $(0.005)$ \\
\hline \multicolumn{5}{|l|}{ Area of productive land } \\
\hline $20 \%$ land gain & $0.747 * * *$ & $(0.141)$ & & \\
\hline $20 \%$ land loss & $-1.491 * * *$ & $(0.239)$ & & \\
\hline Land & & & $0.0336^{* * *}$ & $(0.005)$ \\
\hline \multicolumn{5}{|l|}{ Condition of public infrastructure } \\
\hline $20 \%$ infrastructure gain & 0.185 & $(0.331)$ & -0.471 & $(0.343)$ \\
\hline $20 \%$ infrastructure loss & $-1.126^{* * *}$ & $(0.214)$ & $-1.155^{* * *}$ & $(0.234)$ \\
\hline $20 \%$ infrastructure loss*time & & & $-0.012 * *$ & $(0.006)$ \\
\hline \multicolumn{5}{|l|}{ Distribution of benefits } \\
\hline Equal & -0.171 & $(0.173)$ & -0.173 & $(0.199)$ \\
\hline \multicolumn{5}{|l|}{ Public involvement } \\
\hline Consulted & $0.932 * * *$ & $(0.324)$ & $0.539^{*}$ & $(0.305)$ \\
\hline Consulted standard deviation & & & $0.922 * * *$ & $(0.211)$ \\
\hline Consulted*age & $0.0166^{*}$ & $(0.00963)$ & $-0.0232 *$ & $(0.012)$ \\
\hline Empowered & $0.651^{* * *}$ & $(0.199)$ & $0.401 *$ & $(0.225)$ \\
\hline Empowered*age & $0.0161 * *$ & $(0.00853)$ & & \\
\hline \multicolumn{5}{|l|}{ Risk of failure } \\
\hline Medium & $0.506^{* *}$ & $(0.250)$ & 0.308 & $(0.251)$ \\
\hline Low & $0.776 * * *$ & $(0.250)$ & $0.714 * * *$ & $(0.254)$ \\
\hline ASCs & & & & \\
\hline
\end{tabular}




\begin{tabular}{lllll}
\hline ASC2 & $0.606^{* * *}$ & $(0.189)$ & $0.749^{* * *}$ & $(0.203)$ \\
ASC3 & 0.305 & $(0.201)$ & 0.147 & $(0.200)$ \\
ASC2 standard deviation & $-0.374^{* * *}$ & $(0.130)$ & $0.554^{* * *}$ & $(0.141)$ \\
& & & \\
Observations & 1,115 & 683 & \\
Log likelihood & -861.64 & -585.42 & \\
Pseudo $\mathbf{R}^{2}$ & 0.297 & 0.240 & \\
\hline Notes:******* & & & \\
\end{tabular}

Table 5: Marginal rate of substitution for significant attributes - the percentage of productive land individuals are willing to lose in order to avoid a loss/achieve a change in other attributes.

\begin{tabular}{lll}
\hline & Landholders & Townspeople \\
\hline Avoid a $20 \%$ loss of biodiversity & $13.48^{* * *}$ & $24.80^{* * *}$ \\
Avoid a $20 \%$ loss of public infrastructure & $15.10^{* * *}$ & $31.44^{* * *}$ \\
Shift from no consultation to consultation & $12.77^{* * *}$ & $17.36^{* * *}$ \\
Shift from no consultation to empowerment & $8.98^{* * *}$ & $11.13^{* *}$ \\
Shift from high risk to medium risk of failure & $6.78^{* *}$ & \\
Shift from high risk to low risk of failure & $10.41^{* * *}$ & $21.31^{* * *}$ \\
\hline Notes: ${ }^{* * *}, * *, *$ denotes significance at the $99 \%, 95 \%$ and $90 \%$ level of confidence respectively.
\end{tabular}

For attributes with interaction terms, MRS are measured at the mean values for the relevant sample, defined in Table 2. 
Table 6: Marginal rate of substitution for biodiversity relative to productive land, according to the perceived future extent of salinity.

\begin{tabular}{lll}
\hline Percentage points of land one is prepared to lose to: & Landholders & Townspeople \\
\hline Avoid $20 \%$ loss of biodiversity where: & $9.64^{* * *}$ & $16.06^{* *}$ \\
Future extent of salinity $=10 \%$ & $12.45^{* * *}$ & $20.86^{* * *}$ \\
Future extent of salinity $=25 \%$ & $17.12^{* * *}$ & $28.86^{* * *}$ \\
Future extent of salinity $=50 \%$ & $21.80^{* * *}$ & $36.87^{* * *}$ \\
Future extent of salinity $=75 \%$ & & \\
\hline
\end{tabular}

Notes: $* * *, * * *$ denotes significance at the $99 \%, 95 \%$ and $90 \%$ level of confidence respectively.

For attributes with interaction terms, MRS are measured at the mean values for the relevant sample, defined in Table 2.

Table 7: Marginal rate of substitution for biodiversity relative to productive land, according to the time spent living in the Shire.

\begin{tabular}{lcc}
\hline Percentage points of land one is prepared to lose to: & Landholders & Townspeople \\
\hline Avoid $20 \%$ loss of biodiversity where: & $19.42^{* * * *}$ & $17.41^{* * *}$ \\
Time spent living in shire $=10$ years & $15.88^{* * * *}$ & $26.49 * * *$ \\
Time spent living in shire $=25$ years & $9.97 * * *$ & $41.62 * * *$ \\
Time spent living in shire $=50$ years & \\
\hline Notes: $* * * * *, *$ denotes significance at the $99 \%, 95 \%$ and $90 \%$ level of confidence respectively.
\end{tabular}

For attributes with interaction terms, MRS are measured at the mean values for the relevant sample, defined in Table 2. 
Table 8: Marginal rate of substitution for public infrastructure relative to productive land, according to the time spent living in the Shire.

\begin{tabular}{lll}
\hline Percentage points of land one is prepared to lose to: & Landholders & Townspeople \\
\hline Avoid $20 \%$ loss of public infrastructure where: & & \\
Time spent living in shire $=10$ years & $\mathrm{n} / \mathrm{a}$ & $26.92^{* * *}$ \\
Time spent living in shire $=25$ years & $\mathrm{n} / \mathrm{a}$ & $32.48^{* * *}$ \\
Time spent living in shire $=50$ years & $\mathrm{n} / \mathrm{a}$ & $41.74^{* * *}$ \\
\hline Notes: ***,*** ${ }^{*}$ denotes significance at the $99 \%, 95 \%$ and $90 \%$ level of confidence respectively.
\end{tabular}

Table 9: Marginal rate of substitution for the level of community involvement relative to productive land, according to the age of the respondent.

\begin{tabular}{lll}
\hline Percentage points of land one is prepared to lose to: & Landholders & Townspeople \\
\hline Shift from no consultation to consultation where: & & \\
Age $=25$ & 7.02 & $33.06^{* * *}$ \\
Age $=35$ & $9.25^{* *}$ & $26.16^{* * *}$ \\
Age $=50$ & $12.59^{* *}$ & $15.81^{*}$ \\
Age $=75$ & $18.17^{* * *}$ & 1.44 \\
Shift from no consultation to empowerment where: & & \\
Age $=25$ & 3.42 & $\mathrm{n} / \mathrm{a}$ \\
Age $=35$ & $5.58^{*}$ & $\mathrm{n} / \mathrm{a}$ \\
Age $=50$ & $8.81^{* * *}$ & $\mathrm{n} / \mathrm{a}$ \\
Age $=75$ & $14.20^{* * *}$ & $\mathrm{n} / \mathrm{a}$ \\
\hline Notes: $* * * * * *$ denotes significance at the $99 \%, 95 \%$ and $90^{*} \%$ level of confidence respectively.
\end{tabular}




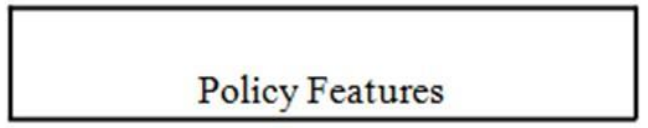

\begin{tabular}{|l|l|l|}
\hline Policy A & Policy B & Policy C \\
\hline
\end{tabular}

\begin{tabular}{|l|}
\hline Asset Protection \\
\hline Level of biodiversity \\
\hline Area of productive land \\
\hline Condition of public infrastructure \\
\hline
\end{tabular}

\begin{tabular}{|c|c|c|}
\hline Current level & $-20 \%$ & Current level \\
\hline Current level & $+20 \%$ & $+20 \%$ \\
\hline$+20 \%$ & $+20 \%$ & $-20 \%$ \\
\hline
\end{tabular}

\section{Risk of Failure}

Public involvement in decision

\begin{tabular}{|l|l|l|}
\hline Low & Medium & Low \\
\hline
\end{tabular}

\section{Distribution of benefits}

If these were the only options available, which would you choose?

Tick only one

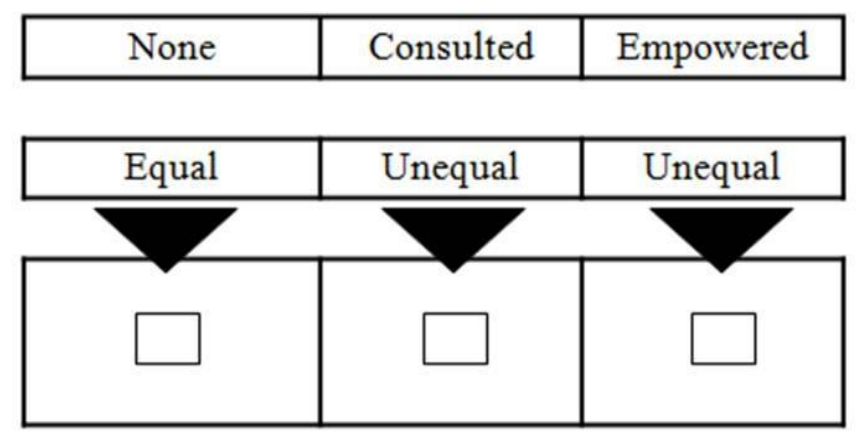

Figure 1: Example of a choice scenario. 


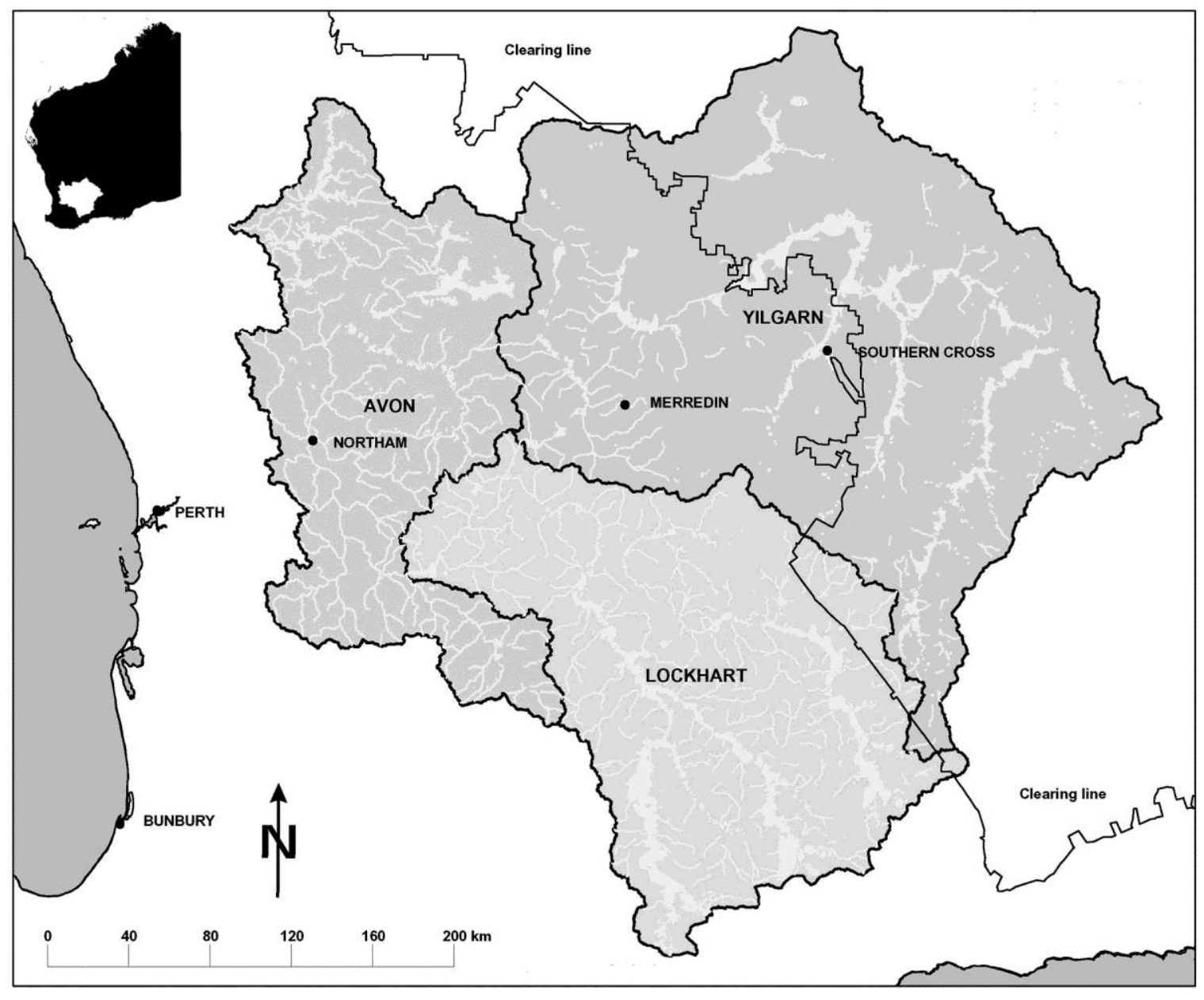

Figure 2: The Avon NRM subregions (Source: Wheatbelt NRM Inc.). 


\section{Appendix}

This appendix provides detailed examples of how the partworths reported in the main text are derived from the reported estimation results.

Assume that the utility function estimated in a choice experiment takes the form:

$U=\beta_{1} X_{1}+\left(\beta_{2}+\beta_{3} Z\right) X_{2}+\beta_{4} X_{4}$

where $X_{1}$ and $X_{2}$ are attributes, $Z$ an individual specific variable that affects the marginal utility of $\mathrm{X}_{2}$, and $\mathrm{X}_{4}$ a continuous attribute that is used as the numeraire. The marginal rate of substitution, or partworth, for $\mathrm{X}_{1}$ and $\mathrm{X}_{2}$ can be defined, respectively, as:

$P W_{1}=\beta_{1} / \beta_{4}$

$P W_{2}=\left(\beta_{2}+\beta_{3} Z\right) / \beta_{4}$

Where there are multiple interaction variables, they need to be included equivalently.

Where interaction variables are included with an attribute, one must recognise that the marginal utility of the attribute changes as the interaction variable changes, and hence one must be explicit about the point where the partworth is calculated. Initial partworths (Table 5) are reported at townspeople and landholder sample means. Note that at the estimation stage interaction variables are defined as combined-sample mean deviations (i.e. for townspeople and landholder samples combined). Here, the separate townspeople and landholder sample means are used to account for differences in means across the two samples.

For example, for the townspeople sample, the mean value for the "time spent living the shire" is -7.91; that is, the average time for town dwellers is 7.91 years less than the combined townspeople and landholder sample average. Similarly the value for perceived threat is 4.13; that is, the average perceived threat held by townspeople is 4.13 units greater than the combined sample average.

As a result, the percentage points of land one is prepared to lose to avoid a $20 \%$ loss in biodiversity, evaluated at the mean for the relevant sample, is given by:

$-(-0.950-0.02 *(-7.91)-0.0107 *(4.13)) / 0.0336=24.8($ see Table 5$)$

This uses the estimated parameters from Table 4, and sample means.

In the cases where the partworth is evaluated at a particular level of the attribute one must calculate the appropriate adjustment to the variable.

For example, the combined sample mean (for landholders+townspeople) of the threat index is -33.2. Therefore the partworth for a townsperson with a zero score for the threat index is given by: 
$-(-0.950-0.02 *(-7.91)-0.0107 *(-33.2)) / 0.0336$

And that for a townsperson with a score for 10, the partworth is given by:

$-(-0.950-0.02 *(-7.91)-0.0107 *(-33.2+10)) / 0.0336=16.1$ (see Table 6$)$

In the case of the landholders, a further adjustment is required. The marginal utility of land loss is defined as the marginal utility associated with a $20 \%$ loss of land (because a dummy variable is employed to identify this state). As a result, the coefficient on land loss in Table 4 $(-1.491)$ is divided by a factor of 20 (giving -0.0746) so that one can compare the values for townspeople and landholders.

All partworths reported in the paper are calculated in this manner, making appropriate adjustments for different sample means. 